\title{
ESTIMATIVA DO CUSTO DE IMPLANTAÇÃO DE SISTEMA DE TERRACEAMENTO, UTILIZANDO-SE O SISTEMA DE INFORMAÇÕES GEOGRÁFICAS. ESTUDO DE CASO: BACIA DO RIO CAXANGÁ, PR
}

\author{
Nori Paulo Griebeler ${ }^{1}$, Daniel Fonseca de Carvalho $^{2}$ \& Antonio Teixeira de Matos ${ }^{3}$
}

\begin{abstract}
RESUMO
O presente estudo foi realizado com o propósito de estimar o custo de implantação de sistema de terraceamento para a bacia hidrográfica do Rio Caxangá, localizada no noroeste do Estado do Paraná utilizando-se, para isTo, um sistema de informações geográficas, SIG. O espaçamento entre terraços foi obtido considerando-se o tipo, uso e manejo do solo e a declividade do terreno. Para a estimativa do espaçamento entre terraços foram utilizadas as equações propostas por Bertoni, Bentley e Lombardi Neto. A bacia estudada apresentou $91,0 \%$ da área total com declividade menor que $8,0 \%$, caracterizando uma região com pequeno risco de erosão. As equações propostas por Bertoni e por Lombardi Neto estimaram custos de implantação em torno de 10,8 e 35,0\%, respectivamente, mais baixos quando comparadas com a equação proposta por Bentley. A utilização do SIG possibilitou uma boa caracterização da região, podendo ser utilizada como importante ferramenta em estudos de conservação de solo e do meio ambiente.
\end{abstract}

Palavras-chave: terraceamento, conservação do solo, SIG

\section{ESTIMATE OF THE ESTABLISHMENT COST OF A TERRACING SYSTEM USING GEOGRAPHICAL INFORMATION SYSTEMS. CASE STUDY: CAXANGA RIVER WATERSHED, PARANA STATE, BRAZIL}

\begin{abstract}
This study was conducted in order to estimate the establishment cost of terracing system in the Caxanga River watershed, in the northwest of Parana State, Brazil, using GIS (Geographical Information Systems). Terrace spacing was obtained by considering soil type, use, management and SLONE, using Bertoni, Bentley and Lombardi Neto equations. The studied watershed showed $91.0 \%$ of its whole area with a slope under $8.0 \%$, which characterizes the region with low risk of erosion. The equations proposed by Bertoni and Lombardi Neto estimated establishment costs about 10.8 and $35.0 \%$, respectively, lower than that obtained by using Bentley equation. A good characterization of the studied region was possible with GIS, therefore it may be used as an important tool in soil conservation and environment studies.
\end{abstract}

Key words: terracing, soil conservation, GIS

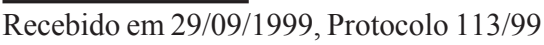

${ }^{1}$ MS. Engenharia Agrícola. Doutorando em Engenharia Agrícola, UFV, Viçosa, MG. Fone: (0xx31) 8992734

${ }^{2}$ Prof. Adjunto, DE/IT/UFRRJ, CEP 23851 - 970, Seropédica, RJ. E-mail: carvalho@ufrrj.br

${ }^{3}$ Prof. Adjunto, Departamento de Engenharia Agrícola, UFV. E-mail : atmatos@mail.ufv.br 


\section{INTRODUÇ̃̃O}

A erosão dos solos é um extenso, sério e crescente problema no Brasil, onde se perdem, a cada ano, 600 milhões de toneladas de solo agrícola, devido à erosão e ao uso inadequado do solo. Segundo a Federação da Associação dos Engenheiros Agrônomos do Brasil (FAEAB) essas perdas correspondem a uma perda anual de $0,5 \%$ da área nacional ocupada por lavouras, considerando-se uma camada arável de $20 \mathrm{~cm}$ e densidade de $1,0 \mathrm{~g} \mathrm{~cm}^{-3}$ (Bahia et al., 1992).

A erosão tende a elevar os custos de produção dos produtos agropecuários, uma vez que aumenta a necessidade de uso de corretivos e fertilizantes e reduz a eficiência operacional das máquinas, além dos custos adicionais com as próprias práticas para controle da erosão.

A erosão hídrica do solo constitui-se no principal impacto da agricultura intensiva no Paraná e, apesar de todo o esforço já realizado no Estado para controlá-la, ainda alcança proporções alarmantes. Informações oriundas de pesquisas mostram que, anualmente, cerca de 15 a $20 \mathrm{t} \mathrm{ha}^{-1}$ de solo são perdidas nas áreas intensivamente mecanizadas (Paraná, 1994). Kronen, citado por Parchen \& Bragagnolo (1991) salienta que uma perda média de solo de $20 \mathrm{t} \mathrm{ha}^{-1}$ ano $^{-1}$ representa, no Estado, uma perda anual de nutrientes equivalente a US\$ 250 milhões. Segundo dados de pesquisa obtidos por Schmidt (1989) o Estado do Rio Grande do Sul perde, em termos médios, mais de $40 \mathrm{tha}^{-1} \mathrm{ano}^{-1}$ nas áreas cultivadas, que totalizam seis milhões de hectares.

O terraceamento de terras agrícolas representa uma das práticas mais difundidas e utilizadas pelos agricultores para controlar a erosão hídrica, constituindo-se na mais importante prática mecânica de controle da erosão. Segundo CODASP (1994) este sistema consiste em um conjunto de canais, adequadamente espaçados e dispostos perpendicularmente à declividade do terreno, com o objetivo de reter e infiltrar ou interceptar e conduzir, com velocidade controlada, o deflúvio superficial originário de chuvas que excedam a capacidade de infiltração de água no solo; sua eficiência depende, basicamente, do correto dimensionamento do espaçamento entre terraços e de sua seção transversal, seja para armazenamento ou para condução de água.

O custo de construção e manutenção de um sistema de terraceamento é relativamente alto, o que requer, antes da adoção dessa tecnologia, um estudo criterioso das condições locais, como clima, solo, sistema de cultivo, culturas a serem implantadas, relevo do terreno e equipamento disponível, para que se tenha segurança e eficiência no controle da erosão. O rompimento de um terraço pode levar à destruição dos demais que estiverem a jusante, podendo ocasionar grandes prejuízos à área cultivada.

Em linhas gerais, em um terreno de topografia mais plana o plantio em contorno ou a rotação de culturas é suficiente para o controle da erosão, porém à medida que vai aumentando a declividade, pode-se necessitar de faixas de retenção ou de terraços. Em áreas muito acidentadas o reflorestamento ou o uso de pastagens pode ser o único cultivo recomendado (Bertoni \& Lombardi Neto, 1990).

Tendo em vista as grandes perdas anuais de solo decorrentes do uso inadequado de práticas de conservação, tem-se a necessidade de uma ação efetiva para redução dessas perdas e dos prejuízos a elas associados. A utilização de técnicas de geoprocessamento constitui-se em instrumento de grande potencial para o estabelecimento de planos integrados de conservação do solo e da água, que permitam a racionalização das operações agrícolas e a conseqüente economia de capital e tempo.

Este trabalho teve por objetivo estimar o custo de implantação de sistema de terraceamento em bacia hidrográfica, com base na declividade, tipo, uso e manejo do solo, fazendo-se uso de um sistema de informações geográficas.

\section{MATERIAL E MÉTODOS}

Para a realização do estudo, considerou-se a bacia do Ribeirão do Caxangá, localizada no município de Nova Esperança, noroeste do Estado do Paraná, entre os paralelos $23^{\circ} 05^{\prime}$ e $23^{\circ} 15^{\prime} \mathrm{S}$ e meridianos $52^{\circ} 00^{\prime}$ e $52^{\circ} 15^{\prime} \mathrm{W}$. A região se caracteriza por apresentar topografia suave e predomínio do minifúndio na estrutura fundiária. Os solos encontrados são classificados como Latossolo Roxo e Terra Roxa Estruturada (EMBRAPA, 1984).

Neste trabalho foi utilizada uma carta topográfica do IBGE, com escala de 1:50.000 e eqüidistância entre curvas de nível de $20 \mathrm{~m}$, na qual a bacia de interesse foi identificada e copiada para a forma digital vetorial utilizando-se o software para digitalização TOSCA 2.12. No mesmo software, os arquivos de vetores gerados foram editados e preparados para a geração das imagens.

Utilizando-se o software IDRISI for Windows, versão 1.0, o vetor foi interpolado, gerando uma imagem de elevação do terreno, com tamanho de pixel de 6 × $6 \mathrm{~m}$, que foi filtrada para a correção de falhas ocorridas durante a geração da topologia de elevação; em seguida, para a subdivisão da bacia em faixas de declividades gerou-se uma imagem de declividade, em percentagem, conforme recomendações feitas por Paraná (1994), para a implantação de 4 tipos de terraceamento: 1) terraços de base larga (declividade $4-8 \%$ ), 2) terraços de base média (declividade $8-12 \%$ ), 3 ) terraços de base estreita (declividade $12-18 \%$ ) e 4) terraços em patamar (declividade $18-50 \%$ ). $\mathrm{Na}$ Figura 1 está apresentado um fluxograma simplificado dos procedimentos utilizados para a obtenção das imagens.

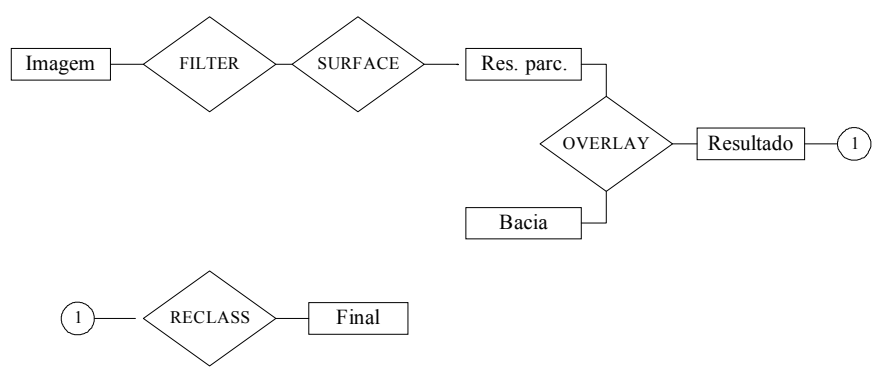

Figura 1. Fluxograma simplificado das operações realizadas para a obtenção das imagens utilizadas para quantificação das áreas relativas a cada declividade

Para se estabelecer o espaçamento entre terraços, foram utilizadas as equações estabelecidas por Bertoni (Bertoni \& Lombardi Neto, 1990):

$$
\mathrm{EV}=0,4518 \cdot \mathrm{K} \cdot \mathrm{D}^{0,58}
$$

e por Bentley (Oliveira et al., 1992): 


$$
\mathrm{EV}=\left(2+\frac{\mathrm{D}}{\mathrm{X}}\right) \cdot 0,305
$$

em que

$$
\text { EV - espaçamento vertical (m) }
$$

D - declividade (\%)

$\mathrm{K}$ e X - índices variáveis conforme o tipo de solo, adimensional.

Os valores de $\mathrm{K}$ e X correspondem, respectivamente, a 0,83 e 3,50, para solos de textura arenosa, e 0,95 e 2,50 para textura argilosa. Para Terra Roxa, K é de 1,21 e, para solos de textura média, o valor de Xé 3,00.

Pelo fato da Eq. 1, proposta por Bertoni, não levar em consideração o tipo de cobertura vegetal e de preparo do solo, Lombardi Neto et al. (1994) propuseram uma equação mais completa, que contemplou esses fatores:

$$
\mathrm{EV}=0,4518 \cdot \mathrm{K} \cdot \mathrm{D}^{0,58} \cdot \frac{(\mathrm{U}+\mathrm{M})}{2}
$$

em que U é um índice empírico que reflete a cobertura vegetal, adimensional, e M um índice empírico que considera o preparo do solo e o manejo de restos culturais, adimensional.

Para o cálculo do espaçamento vertical, adotaram-se os valores de $1,21,2,50,1,75$ e 1,00 para $\mathrm{K}, \mathrm{X}, \mathrm{U}$ e $\mathrm{M}$, respectivamente (Oliveira, 1992). Esses valores correspondem a solo Latossolo Roxo, ocupação com pastagens e capineiras, preparado com grades leves e niveladoras e com os restos culturais parcialmente incorporados ao solo, condições de uso e manejo do solo verificadas na região.

Os valores de declividade utilizados no cálculo do espaçamento entre terraços, foram os correspondentes aos limites superiores das faixas de declividades mencionadas, considerando-se esta a situação mais desfavorável, a não ser para a declividade máxima encontrada nas bacias, em que se considerou o próprio valor encontrado.

Para as microbacias 1 e 3, o valor máximo de declividade encontrado foi de $14 \%$ e, para a microbacia 2 , o valor máximo foi de $12,0 \%$. Uma vez calculado o espaçamento vertical, o espaçamento horizontal $(\mathrm{EH})$ pôde ser calculado da seguinte forma:

$$
\mathrm{EH}=\mathrm{EV} \cdot \frac{100}{\mathrm{D}}
$$

O cálculo do custo do sistema de terraceamento foi realizado utilizando-se valores apresentados por IAPAR (1978) obtidos para solo do tipo Latossolo Roxo, utilizando-se trator de $50 \mathrm{HP}$ e arado de três discos. Para terraços de base larga e estreita e declividade média de 6 a $7 \%$, o custo por quilômetro corresponde, para esta situação, a US\$ 51,20 e US\$ 18,48 , respectivamente e para terraços de base média o custo por quilômetro foi estimado fazendo-se uma relação entre os custos de terraços de base larga e estreita, obtendo-se o valor de US\$ 32,72 .
Com a imagem reclassificada nas faixas de declividade recomendadas e de posse dos custos apresentados, utilizou-se o módulo ESCALAR do software IDRISI, para cada microbacia e em cada classe de declividade. Com base na área de cada classe de declividade, obtida no módulo AREA e no espaçamento horizontal calculado segundo as três equações, estimou-se o comprimento total de terraços a serem construídos em cada microbacia, por meio da conversão deste espaçamento em área; enfim, utilizando-se os custos para cada tipo de terraço, estimou-se o custo total para sua implantação.

\section{RESULTADOS E DISCUSSÃO}

Na Figura 2A é apresentada a bacia em estudo, subdividida em três microbacias e, na Figura 2B, a bacia, classificada em faixas de declividade.

(A)

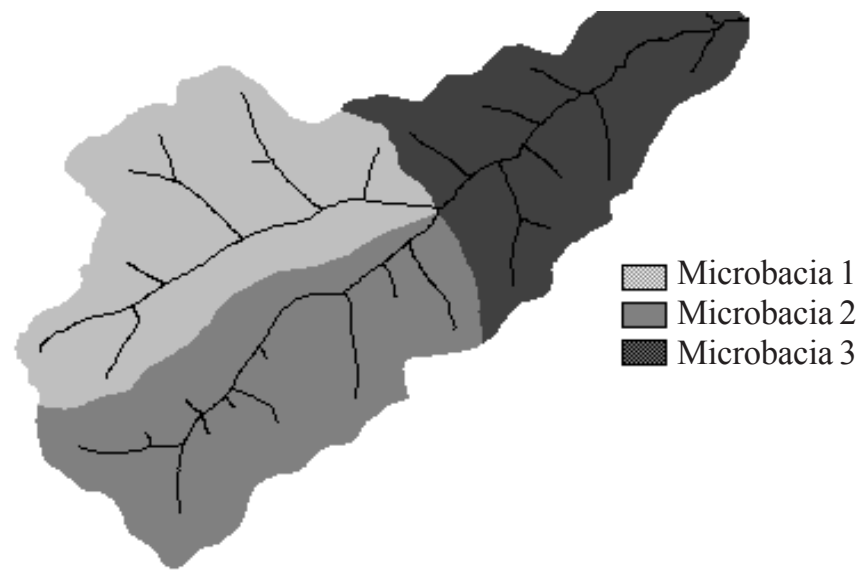

(B)

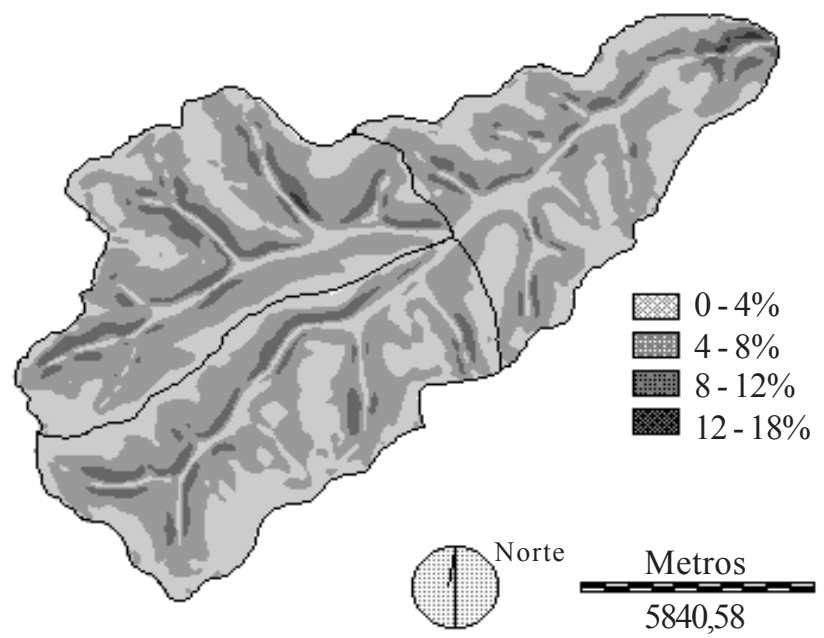

Figura 2. Imagem da bacia do ribeirão do Caxangá A. subdividida em três microbacias B. classificada em quatro faixas de declividade

A área da bacia estudada é de 14.460,2 ha, predominando áreas com declividade suave, inferior a 8,0\%, caracterizando-a como uma bacia com baixo risco erosivo.

A área de cada classe de declive, o espaçamento vertical e horizontal, obtidos pelas três metodologias, e os custos de implantação do sistema de terraços, são apresentados na Tabela 1. 
Tabela 1. Valores de espaçamento entre terraços e custo de terraceamento em função da área e da classe de declividade

\begin{tabular}{|c|c|c|c|c|c|c|c|c|c|c|c|}
\hline \multirow[b]{2}{*}{ Sub-bacia } & \multirow[b]{2}{*}{$\begin{array}{c}\text { Classe } \\
(\%)\end{array}$} & \multirow{2}{*}{$\begin{array}{l}\text { Área } \\
\text { (ha) }\end{array}$} & \multicolumn{3}{|c|}{ Bertoni } & \multicolumn{3}{|c|}{ Bentley } & \multicolumn{3}{|c|}{ Lombardi Neto } \\
\hline & & & $\begin{array}{l}\mathrm{EV} \\
(\mathrm{m})\end{array}$ & $\begin{array}{l}\mathrm{EH} \\
(\mathrm{m})\end{array}$ & $\begin{array}{c}\text { Custo } \\
\text { Total (US\$) }\end{array}$ & $\begin{array}{l}\text { EV } \\
(\mathrm{m})\end{array}$ & $\begin{array}{l}\mathrm{EH} \\
(\mathrm{m})\end{array}$ & $\begin{array}{c}\text { Custo } \\
\text { Total (US\$) }\end{array}$ & $\begin{array}{l}\mathrm{EV} \\
(\mathrm{m})\end{array}$ & $\begin{array}{l}\mathrm{EH} \\
(\mathrm{m})\end{array}$ & $\begin{array}{c}\text { Custo } \\
\text { Total (US\$) }\end{array}$ \\
\hline \multirow{3}{*}{1} & $0-4^{*}$ & $1.784,37$ & - & - & - & - & - & - & - & - & - \\
\hline & $8-12$ & 543,54 & 2,3 & 19,3 & $9.214,00$ & 2,1 & 17,3 & $10.280,00$ & 3,2 & 26,5 & $6.711,00$ \\
\hline & $12-18$ & 8,53 & 2,5 & 18,1 & 87,00 & 2,3 & 16,5 & 96,00 & 3,5 & 24,9 & 63,00 \\
\hline \multirow{2}{*}{2} & $0-4^{*}$ & $2.266,24$ & - & - & - & - & - & - & - & - & - \\
\hline & $12-18^{* *}$ & - & - & - & - & - & - & - & - & - & - \\
\hline \multirow{4}{*}{3} & $0-4^{*}$ & $1.812,79$ & - & - & - & - & - & - & - & - & - \\
\hline & $4-8$ & $2.172,85$ & 1,8 & 22,9 & $48.580,00$ & 1,6 & 19,8 & $55.928,00$ & 2,5 & 31,5 & $35.517,00$ \\
\hline & $8-12$ & 286,16 & 2,3 & 19,3 & $4.851,00$ & 2,1 & 17,3 & $5.412,00$ & 3,2 & 26,5 & $3.533,00$ \\
\hline & $12-18$ & 14,39 & 2,5 & 18,1 & 147,00 & 2,3 & 16,5 & 161,00 & 3,5 & 24,9 & 107,00 \\
\hline
\end{tabular}

* Nessa faixa de declividade, a utilização de terraceamento foi considerada desnecessária

** Nessa sub-bacia não ocorreu declividade superior a $12 \%$

A equação de Bentley proporcionou a obtenção de menores espaçamentos verticais e maiores custos de terraceamento. Esta equação, embora seja a mais empregada no Brasil, utiliza coeficientes que não foram obtidos para as nossas condições de campo (EMBRAPA, 1980, citado por Oliveira et al., 1992).

A equação proposta por Bertoni proporcionou a estimativa de espaçamento entre terraços, em média $10,8 \%$ mais altos, quando comparada à proposta por Bentley diminuindo, assim, o número de terraços locados. Por se tratar de uma equação desenvolvida para climas tropicais, ela é mais adaptada às condições estudadas devendo, assim, fornecer resultados mais confiáveis que aquela proposta por Bentley.

Com a equação apresentada por Lombardi Neto et al. (1994) que considera a cobertura vegetal e o tipo de preparo do solo, foram obtidos espaçamentos em média $35,0 \%$ maiores que os obtidos, utilizando-se a equação de Bentley, o que provocará uma redução maior no número de terraços construídos.

Na Figura 3 estão representados os custos de implantação do sistema de terraceamento, em função da classe de declividade, da área de cada classe e do espaçamento vertical estimado. Nesta figura, verifica-se que os menores custos de implantação foram estimados com a utilização da equação de Lombardi Neto, seguida pela de Bertoni, para todas as condições estudadas. É importante observar que os resultados obtidos pelas equações desenvolvidas a nível de Brasil, Bertoni \& Lombardi Neto (1990) e Lombardi Neto et al. (1994) embora aumentem os espaçamentos entre terraços diminuindo, conseqüentemente, os custos, aumentam também a área de coleta de água da chuva. Este fator, para regiões com altas intensidades de precipitação, comuns em climas tropicais, provocará um maior volume de escoamento superficial podendo, em conseqüência, provocar o rompimento dos terraços acarretando, desta forma, grandes prejuízos.

O menor espaçamento entre terraços permitirá, devido ao menor volume de escoamento de água coletado, que a seção transversal do terraço possa ser inferior àquelas obtidas para grandes espaçamentos, reduzindo o número de passadas de máquina para a sua construção. Desta forma, o custo de implantação do sistema é dependente do espaçamento vertical entre terraços, não podendo ser estimado corretamente sem a consideração da seção necessária para contenção do escoamento superficial produzido na área.

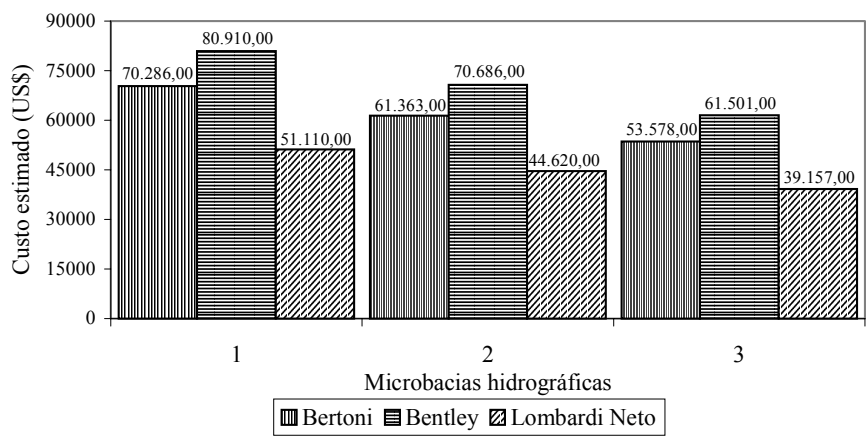

Figura 3. Representação gráfica dos custos de implantação do sistema de terraceamento, pelas três metodologias, para cada uma das microbacias

O uso do SIG, além de facilitar o estudo da declividade no mapa, favoreceu a estimativa da implantação do sistema de terraceamento. De posse do mapa de declividades da bacia (Figura 2B) tornou-se possível à delimitação das áreas a serem implantadas com cada tipo de terraço, o que poderá otimizar o uso e a movimentação de máquinas agrícolas.

\section{CONCLUSÕES}

Com base nos resultados obtidos, pode-se concluir que:

1. A bacia estudada apresenta a maior parcela de sua área, com pequena declividade sendo, portanto, o risco de erosão não muito acentuado.

2. A metodologia proposta por Bertoni e por Lombardi Neto, estimou custos em torno de 10,8 e $35,0 \%$, respectivamente, mais baixos para espaçamento de terraços, quando comparada com a proposta por Bentley.

3. A utilização do sistema de informações geográficas possibilitou um prognóstico de custos do terraceamento, tornando-se uma importante ferramenta em estudos da conservação do solo e do meio ambiente.

4. A estimativa do custo de implantação de sistema de terraceamento deverá levar em conta não apenas o tipo de terraço, solo e máquina mas, também, a seção que este terraço deverá apresentar em função do volume de água coletado. 


\section{REFERÊNCIAS BIBLIOGRÁFICAS}

BAHIA,V.G.; CURI, N.; CARMO, D.N.; GRANATE SÁ, J.J.; MARQUES, M. Fundamentos de erosão do solo. Informe Agropecuário, Belo Horizonte, v.16, n.176, p.25-31. 1992.

BERTONI, J.; LOMBARDI NETO, F. Conservação do solo. São Paulo: Ícone, 1990. 355p.

CODASP - Companhia de Desenvolvimento Agrícola de São Paulo. Manual técnico de motomecanização agrícola. São Paulo, 1994. 100p.

EMBRAPA - Empresa Brasileira de Pesquisa Agropecuária; Instituto Agronômico do Paraná. Levantamento e Reconhecimento dos solos do Estado do Paraná. Tomo II, Londrina, 1984.781p. Boletim Técnico 57

IAPAR - Instituto Agronômico do Paraná. Composição de custos para sistemas de terraceamento em regiões do Estado do Paraná. Relatório Técnico Anual - Programa Manejo e Conservação de Solos, Londrina, 1978. 260p.
LOMBARDINETO, F.; BELLINAZZI JÚNIOR, R.; LEPSCH, I.F.; OLIVEIRA, J.B.; BERTOLINI, D.; GALETI, P.A.; DRUGOWICH, M.I. Terraceamento agrícola. Campinas: Secretaria da Agricultura e do Abastecimento do Estado de São Paulo, Coordenadoria de Assistência Técnica Integral, 1994.39p. Boletim Técnico CATI, 206

OLIVEIRA, G.C.; PEREIRA, J.C.; MESQUITA, M. da G.B.F. Espaçamento entre terraços em função dos fatores que afetam as perdas por erosão. Informe Agropecuário, Belo Horizonte, 1992. v.16n.176. p.51-56.

PARANÁ. Secretaria de Estado da Agricultura e do Abastecimento. Manual técnico do subprograma de manejo e conservação do solo. Curitiba, 1994. 372p.

PARCHEN, C.A.P.; BRAGAGNOLO, N. Erosão e conservação de solos no Paraná. Curitiba: EMATER, 1991. 16p.

SCHMIDT, A.V. Terraceamento na região Sul. In: SIMPÓSIO SOBRE TERRACEAMENTO AGRÍCOLA, 1988, Campinas. Anais... Campinas: Fundação Cargill, 1989. p.23-25. 